\title{
Universal Service: \\ Providing Access to Tertiary Education through E-Learning
}

Francisca E. Anene

\author{
National Open University of Nigeria, Lagos-Nigeria
}

\section{Doi:10.5901/jesr.2013.v3n8p111}

\begin{abstract}
This paper is on the place of e-learning in facilitating access to tertiary education and the extent to which the achievement of universal service in the communications sector will affect the actualisation of e-learning objectives for tertiary education. The paper considers the problem of lack of capacity as a barrier to entry into the tertiary education sector, e-learning as a practical solution and universal communications service as a necessary ingredient for e-learning. The paper also looks at practical challenges posed by poor telecommunication service and experiences in the National Open University of Nigeria, the only single mode Open and Distance Learning institution in Nigeria.
\end{abstract}

\section{Introduction}

Education has long been recognised as a social service with direct effects on development levels in every nation. Education is even more important in Nigeria, where unemployment is rife resulting in intense competition for the few available jobs. Owing to onerous job requirements and competition for such jobs, tertiary education has become a necessity. Unfortunately, access to tertiary education is severely restricted by lack of carrying capacity in most conventional universities.

This paper is on the place of e-learning in facilitating access to tertiary education and the extent to which the achievement of universal service obligations in the communications sector will affect the actualisation of e-learning objectives for tertiary education. The paper considers the problem of lack of capacity as a barrier to entry into the tertiary education sector, e-learning as a practical solution and universal communications service as a necessary ingredient for e-learning. The paper also looks at practical challenges posed by poor telecommunication service and experiences in the National Open University of Nigeria, the only single mode Open and Distance Learning institution in Nigeria.

\section{Demand-Supply Inequalities in Tertiary Education}

Where tertiary education in Nigeria is concerned, demand far outweighs supply. This inequality is clear from the perennial problem of over-registration of candidates for tertiary education. Each year, millions of candidates register for the Unified Tertiary Matriculation Examinations (UTME) administered by the Joint Admissions and Matriculations Board (JAMB). Of the successful candidates, a substantial percentage is denied admission each year.

Aluede, Idogho and Imonikhe (2012) opined that only $5.2 \%$ to $15.3 \%$ of the thousands of candidates applying for admission into tertiary institutions are given admission each year. Despite the falling standards of education in Nigeria, this inequality in demand and supply is not attributable to mass failure but to lack of carrying capacity in the sense that there is insufficient infrastructure to train these students. The Nigerian Tribune in its July $15^{\text {th }} 2010$ carried a story titled '2010 JAMB, Survival of the Fittest'. The statement which was attributed to the Registrar of JAMB noted that of 867,000 candidates who made the cut-off points for admission under the UTME 
in 2010 , only about 527,000 candidates would be admitted due to lack of sufficient spaces. The 360,000 students who could not be admitted would be required to write the examination the next year as part of the 1,493,604 other candidate who will sit for the examination in 2011. In 2012, a total of 1,503,931 students sat for the UTME while 1,644,100 sat for the 2013 UTME.

Open Distance and E-learning (ODEL) provides a solution to this problem. Owing to its emphasis in self learning and reduced need for face-to-face lectures, capacity issues related with lack of physical infrastructure do not arise. With ODEL the possibility of universal tertiary education becomes a reality. This mode of learning has been used effectively as an alternative means of delivering qualitative tertiary education in more developed nations like the United Kingdom where the Open University remains the largest academic institution with over 240,000 students. In 2006, the OU was ranked highest in students satisfaction and assessment /feedback. It was also ranked among the top six universities in the United Kingdom for quality of teaching, academic support and organisation/management. Through the Open University, Open and Distance learning has been used to increase capacity and train the workforce.

The concept of distance learning in tertiary education is not entirely new in Nigeria. Before the establishment of universities, many Nigerians took correspondence courses. Presently, several tertiary institutions have embraced distance learning as a flexible means of providing tertiary education without limitations as to time or location. Initially, this was achieved through the establishment of satellite campuses and outreach centres. In some institutions like University of Lagos and University of Ilorin, this has metamorphosed into distance learning centres for dual mode tertiary education. In addition, with the revival of the National Open University of Nigeria, single mode ODEL is now available for tertiary education in Nigeria thereby increasing capacity and reducing the need for physical connections between students and their teachers. For Nigeria, elearning holds great potentials for increased access to qualitative tertiary education with added advantages of flexibility and cost effectiveness. It is however, largely dependent on information and communications technology (ICT), access to which is still a struggle in many parts of the nation. Owing to its importance for e-learning, communications service is an essential facility.

Limiting factors such as poverty and insufficient knowledge are the first barriers to effective use of ICT. Where these factors are absent, technical factors such as lack of or poor quality service become the next culprits. By its very nature, the communications sector is characterised by high barriers to entry and huge sunk costs. As a result, investments in the sector are few. Though the profit margin increases on the long run, the cost of entry is very high and not easily recouped. Where an investor invests in the sector and is forced out due to competitive disadvantage, initial investments are usually lost.

Considering the issues associated with the communications sector vis-a-vis its relevance for the development of other sectors, government involvement is necessary, at least, until the sector is fully competitive. Furthermore, the regulator must be active in ensuring that the service is freely available and not restricted by competition.

\section{What is Universal Service?}

Article 1(2) of the EU Universal Service Directive defines 'universal service as the provision of a defined minimum set of services of specified quality to which all end users have access, at an affordable price in the light of national conditions without distorting competition'. Going by current technological advances - particularly in the convergence of telecommunications and ICT media, most countries have set universal service standards with obligations on service providers and/or other regulatory bodies to attain such standards. Universal service standards vary from country to country depending largely on levels of development. Universal service standards in all countries include voice telephony with some countries stretching their standards to include data, number portability and/or disability access to telecommunications services.

Whatever the standards adopted in a particular country, the requisite services must have 
three common features namely availability, accessibility and affordability.

a. Availability does not necessarily mean that there must be one communications terminal per user. Instead, depending on the unique economic realities of the country in question, it refers to reasonable coverage with public or private access to a communications terminal.

b. Accessibility entails qualitative service which is available at a convenient location within walking distance of users. Where this is a public communications terminal, it should be open within convenient hours with an all inclusive design accessible to handicapped or physically challenged users. Users should also be able to get assistance where needed, in their use of the facility.

c. Affordability refers to ability of the consumers to pay for the service. Charges must be a small percentage of per capita income with various payment options and the ability to pay per use of small units of service e.g. single calls or hourly internet rates.

Current universal service standards for Nigeria include voice services, internet services and other network facilities.

In Nigeria, universal service means that $100 \%$ of a designated population are reasonably able to privately subscribe to and use a particular service at a specified quality on an individual, household or institutional basis.

It is instructive to note that the Nigerian definition differentiates between universal access, universal coverage and universal service. Sections 43(a) and 84(1) of the Universal Access and Universal Service Regulations 2007 define universal access to mean where $100 \%$ of a designated population can obtain, at a minimum, public access to a particular service at a specified quality whilst Sections $43(\mathrm{~b})$ and $84(1)$ define universal service to mean where $100 \%$ of a designated population are reasonably able to privately subscribe to and use a particular service at a specified quality on an individual, household or institutional basis (emphases mine). Accordingly, whilst universal access relates to the use of public facilities, universal service relates to the use of private facilities. In Nigeria, telecommunications and internet services are available either privately (through personal telephones and computers) or publicly (through payphones or cybercafés). Due to the cost of personal computers and connection charges, majority of Nigerians patronize cybercafés.

In view of the foregoing and considering the economic realities in Nigeria, reference to the term 'universal service' shall be taken to include both universal access and universal service as defined in the Universal Access and Universal Service Regulations 2007 i.e. the ability of a designated population to obtain communications services through public or private means.

\section{The Legal and Regulatory Framework for Universal Service}

The Nigerian communications sector is regulated by the Nigerian Communications Commission (NCC) under the Nigerian Communications Act 2003 (NCA). The NCC is charged with responsibility to devise, manage and implement the universal access strategy and program in line with the policy and objectives of the Federal Government of Nigeria. In the exercise of its powers, the NCC promulgated the Universal Access and Universal Service Regulations 2007 ('the Regulations') to provide the framework for the design and implementation of universal access and universal service in Nigeria.

One of the objectives of the NCA is the promotion of universal communications services throughout Nigeria. In furtherance of this universal service objective, the NCA also created the Universal Services Provision Fund (hereinafter referred to as 'the Fund') to facilitate the rapid achievement of national policy goals for universal access to telecommunications and information and communication technologies (ICT) services. Some of the objectives for creating the Fund are as follows:

- To contribute to national economic and social development through enhancing the 
universal accessibility and availability of telecommunications and ICT infrastructure and services.

- To facilitate the provision of access to ICT services within a reasonable distance to all persons in Nigeria.

- To facilitate the provision of infrastructural development to rural and underserved areas in a non-discriminatory manner.

- To ensure effective utilization of funds to leverage investments in rural communications.

The Fund is managed by a Board known as the USP Board. The USP Board is charged with the responsibility of supervising and providing broad directions for the management of the Fund and the Fund Managers. The Fund contains monies pooled from several sources, including monies appropriated to it by the National Assembly, contributions to NCC based on levies paid by licensees, gifts, loans and aid.

In line with the universal service objectives of the Fund, the main beneficiaries are unserved areas, underserved areas and underserved groups in Nigeria. Whilst the goal of regulation is to achieve universal service for all Nigerians, the focus of the Fund is on unserved and underserved areas and/or groups because, it is expected that liberalization and competition in service provision will stimulate the achievement of universal service goals in other areas and groups. This is the case, for instance, in urban areas like Lagos, where all the service providers have a strong presence with necessary infrastructure and a viable market for communications services in place.

One of the key points for universal service under the NCA is the availability of relevant services to educational institutions. S113(4) of the NCA provides that the NCC shall, in determining the definition of institutions have regard to the educational, health and other socio-infrastructural needs of Nigerians (emphasis mine). Regulation 44(a)(v) and Regulation 44(b)(v) of the NCA also includes educational institutions in definitions ascribed to universal access and universal service.

The Fund also pays particular attention to the provision of universal access to telecommunications and ICT services in Nigerian institutions of learning, with projects such as the School Access Programme (SAP) - to provide internet access to schools with each beneficiary school receiving 100 computers with full internet access. Other programmes directed at the provision of access to communications services to educational institutions are the Tertiary Institution Access Programme (TIAP) and Creation of E-Libraries.

The Fund also has other projects which though not directly focused on e-learning will facilitate access to communications services for the purpose of e-learning. They include the Connectivity for Development (C4D) Programme - to encourage and facilitate the building of an e-society in Nigeria and promote a digital lifestyle, and the Community Communications Centre (CCC) Project under which the Fund aims to deliver one Community Communications Centre per senatorial district.

Progress made in the provision of communications services in Nigeria has received acclaim in various quarters. In 2010, the International Telecommunications Union (ITU) hailed the Nigerian communications sector as 'one of Africa's biggest success stories in its expansion of telecommunications and ICT'. This is largely due to the liberalisation of telecommunications services and the grant of unified licenses for the provision of voice and data services which has stimulated competition, resulting in the availability of an array of communications and network services with multiple service providers offering diverse services and plans to suit different strata of the society. From 866,782 lines in 2001 when the sector was liberalised, telecommunications connections have risen steadily to $164,892,379$ in April 2013. Teledensity has also risen steadily from $0.73 \%$ in 2001 to $82.25 \%$ in April 2013. The same is true for internet usage. NCC statistics (2013) show that internet usage as at April 2013 was 34,928,770. According to Internet World Stats (2012), internet penetration in Nigeria was estimated at 200,000 in December 2000. Today, Nigeria accounts for $28.9 \%$ of all internet users in Africa. This marked increase in communications connections and usage in Nigeria can be attributed the liberalisation of the communications sector and the deployment of new technologies such as Code Division Multiple Access (CDMA), Broadband and submarine cabling. The result of liberalisation is clear with improved pricing and availability of 
communications services.

The USP Secretariat and Board having been formally constituted, the Fund has commenced activities in fulfilment of its universal service mandate. Requests have been made for proposals to facilitate the SAP and TIAP programmes. The Zaria Community Communications Centre has also been completed. Furthermore, ICT and internet tools and facilities have been delivered to several educational institutions in Nigeria. As of 2009, a total of 474 schools have been provided with fully functional internet and ICT Facilities supplied by the Fund.

\section{Communications Services and E-Learning: Practical Issues}

\subsection{Telecommunications Service in Nigeria}

The above statistics indicate a positive drive towards the attainment of universal service in telecommunications and ICT provision in Nigeria. However, they point more to the general as against the specific. For instance, teledensity refers to the number of telephone lines (including wired residential and business lines) per 100 people. A rough estimate of telephone penetration in a particular location, measurement of teledensity is usually done on a country wide basis. Whilst teledensity may show the extent of telecommunications penetration on a general scale, it does not show the quality of service available. Furthermore, it may not clearly indicate the extent of access to communications services in specific regions, especially when considered in connection with universal service which focuses more on availability, affordability and qualitative service to specific regions and groups. While there may be multiple connections and services available to consumers in cosmopolitan/urban areas where competition drives access and availability of service, it may not be the case for unserved and underserved areas where the subscriber base is usually insufficient to support viable competitive communications projects because of huge sunk costs and high barriers to entry associated with communications service provision. As a result, such unserved or underserved communities will be largely dependent on the achievement of universal service obligations as mandated by the regulator, if they are to benefit from e-learning.

On a related note, achievement of e-learning will, to some extent, depend on quality and affordability of relevant communications services. The USPF Board is charged with the responsibility of enforcing quality standards in unserved and underserved areas. Also, the NCC as the regulator of the communications sector has been working actively in the discharge of its responsibility to protect consumers' interests. The NCC, has taken on this task with significant results. In the past, incidences of poor service quality and network congestion were rife in Nigeria. Though such challenges still arise from time to time, the NCC has made appreciable progress in quality control for telecommunications services.

Unfortunately, the same level of progress is yet to be achieved with regard to internet services. Ituen (2010) opined that slow internet speed is a major impediment to Nigeria's technological growth. It must be noted, however, that consumers in urban areas enjoy better internet service quality with competitive pricing made possible through the deployment of technology and infrastructure by profit driven service providers. Competition and market forces usually drive improvement in service quality and pricing of commodities. The same is true for telecommunications services. With the passage of time, it is expected that technological deployment occasioned by NCC's liberalisation of communications services (particularly the recent deployment of submarine cables and licensing of additional service providers) coupled with soft touch regulation will help to drive down pricing and improve service quality for telecommunications services in Nigeria.

Figures 1 and 2 show a pictorial representation of telecommunications coverage in Nigeria, as provided by two of the major GSM telecommunications service providers - Airtel and MTN respectively. The information depicted in the attached pictures is representative and comparable to coverage for other telecommunications service providers in Nigeria. 


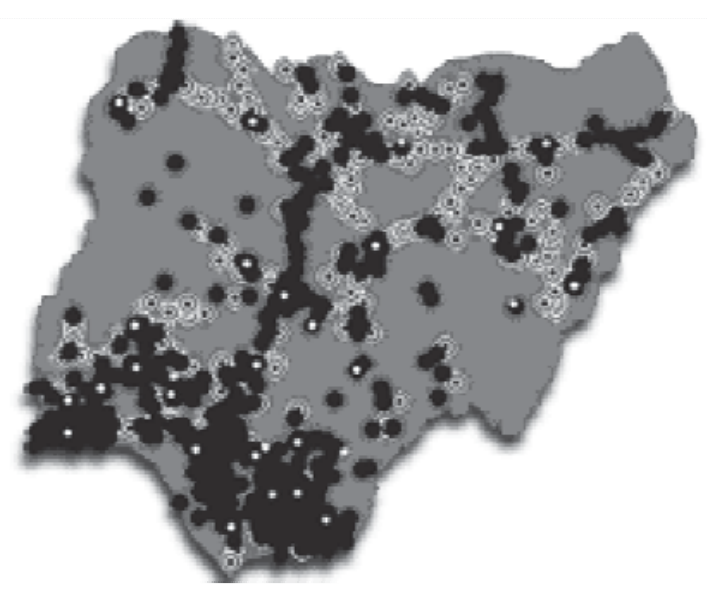

Figure 1: Airtel communications and internet coverage in Nigeria (2011)

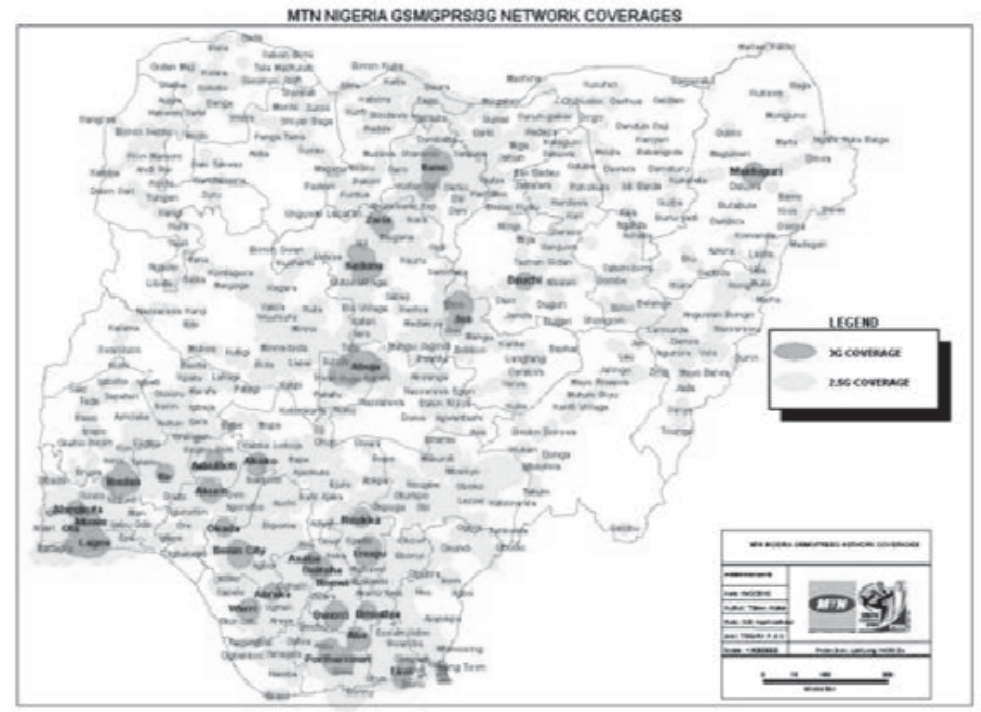

Figure 2: MTN communications and internet coverage in Nigeria (2011)

As shown in the Figures 1 and 2, urban regions like Lagos, Port Harcourt and Abuja are saturated with telecommunications services whilst rural areas enjoy less coverage. In Nigerian urban areas, it is commonplace to find base stations in every locality inclusive of uninhabited areas. As a result, users travelling along urban expressways enjoy telecommunications services because base stations are located even in such uninhabited areas. The same is not the case for unserved and underserved areas where telecommunications infrastructure is usually scanty, with poor quality service.

In a survey conducted by Mishra (2009) at the University of Maiduguri, $71.54 \%$ of respondents identified slow internet connection as the major problem encountered in their use of the internet. This is a common complaint in unserved and underserved regions, for the reasons stated above. In view of the sharp dichotomy in the level of access and quality of communications services available to consumers in different locations, the achievement of universal service 
benchmarks set from time to time will make a marked difference in the provision of services and infrastructure to facilitate e-learning in the unserved and underserved areas of Nigeria.

\subsection{Universal Service and E-learning: Experiences in National Open University of Nigeria}

The National Open University of Nigeria (NOUN) is the only specialist provider of open and distance education in Nigeria. It is also the largest tertiary institution in terms of student population. The main focus of the institution being to educate the Nigerian workforce, NOUN offers over 750 courses of study from certificate to post graduate level. At present, there are over 50 study centres situated at various locations in Nigeria. The Study centre is designed to be the hub of activity with study materials available for pick up-and interactions made possible between students and facilitators, tutors and student counsellors who offer support as required by students.

In line with recent advances in distance education, the emphasis in NOUN is on e-learning. Owing to the continued use of the iLMS platform, admission and course registration are initiated online. Upon completion of registration, students are entitled to hard copy study materials, available for collection from their respective study centres. These course materials are also available online for free download.

Continuous assessment in NOUN is in form of tutor marked assignments (e-TMAs) which students are required to complete online through their personal student portals. E-exams have also been introduced with students writing pre-formatted computer based examinations at designated examination centres.

Most NOUN study centres are located in state capitals or regions where internet service is readily available. Exceptions are Special Prison Study Centers located in certain prisons for access to prison inmates. Internet service is not available to prison inmates so, students in those centers are assessed through hard copy examination questions which are marked manually. Though some of these areas in which NOUN study centres are located would qualify as underserved areas because of the level of internet penetration, students can access the internet through commercial cybercafés - on a pay per view basis or through broadband internet access provided by major telecommunications service providers. There are plans to deploy wireless internet services to facilitate e-learning in all study centres but some study centres do not have ready internet access at present.

The NOUN headquarters where all academic departments and academic staff are located has internet facilities of satisfactory quality. This facilitates study and research as well as preparation and uploading of relevant study materials, e-TMAs and e-Exams. There is a physical library situated at the headquarters for use by staff and students and the NOUN e-library contains a large collection of electronic resources. From our research, there is no conclusive indication whether NOUN has benefitted from the Fund. All academic staff and most administrative staff have access to computer systems with internet access. There are also a number of computer laboratories in the Headquarters.

Whilst it is commendable that the above facilities are in place for e-learning in NOUN, we must not lose sight of the fact that proper service delivery is dependent on quality of service and affordability. It can be argued that anyone who can afford tertiary education should be able to afford commercial internet access. However, service quality is another matter. Though not dependent on users' economic abilities, service quality has a direct effect on the quality of education received by students. Moreover, issues of affordability will arise where students have to purchase internet connection repeatedly to complete assignments which would ordinarily be completed in a single browsing session but become impossible to complete because of service failures.

Complaints regarding internet service quality are recurrent in Nigeria, regardless of location. In NOUN, for instance, students regularly complain of their inability to complete their registration, access relevant information and/or log onto their portals to complete their e-TMAs. Such complaints 
have resulted in deadline extensions to enable students meet their continuous assessment obligations.

\section{A Way Forward}

The e-learning project is commendable and holds positive prospects for increased access to tertiary education in Nigeria. However, e-learning objectives stand the risk of under-achievement in the face of current challenges associated with access and quality of communications service in Nigeria.

The requisite legal and regulatory framework is in place to ensure the success of e-learning in Nigeria. Accordingly, implementation should be carried out with utmost seriousness and urgency if the teeming applicants for tertiary education are going to have a chance at achieving their dreams.

E-learning institutions occupy a unique position as specialist providers of open and distance education in Nigeria. Considering current literacy rates, such institutions are veritable avenues for ensuring the achievement of social justice and qualitative education for all. They must therefore be encouraged to leverage on this unique status to obtain the requisite facilities for the achievement of their e-learning objectives.

Additional physical infrastructure can be put in place but infrastructure will always be limited by time and space. Considering the numbers of students denied admission yearly because of lack of capacity, there is a lot of building to do. This is however not a sustainable solution because demand for tertiary education increases on a yearly basis but continuous construction is impracticable. Conventional universities should therefore borrow a leaf from NOUN and put alternative modes of learning in place as obtains in developed climes. For those who are already exploring the distance learning option, e-learning needs to be seen not as a change in the status quo but an improvement thereon.

As demonstrated in NOUN, single mode ODEL institutions are not restricted with respect to available slots or infrastructure. Communications service being an essential component of qualitative e-learning, the successes of ODEL can be further strengthened through universal access to the service.

The following recommendations are therefore in order:

a. The Fund must expedite action on the completion of on-going rural connectivity projects especially those with educational objectives.

b. Service quality must be monitored on a continuous basis to guarantee the attainment of requisite objectives of the Fund.

c. It is suggested that the Ministries of Education and Communication should jointly generate and monitor a practical road map for the attainment of universal service in educationally disadvantaged communities who will benefit from e-learning.

d. Study centres of e-learning institutions should be equipped with ICT facilities and internet connectivity which will be freely available for student use especially during busy periods such as registration and assessment periods.

\section{References}

Aluede, 0; Idogho, P. and Imonikhe, J. (2012) 'Increasing Access to University Education: Present Challenges and Suggestions for the Future' The African Symposium 3 Volume 12, No. 1, June 2012 pp. $3-13$

Directive 2002/22/EC of 7th March 2002 (Universal Services Directive) pp. L/108/51 - L/108/51 Official J ournal of the European Communities.

ICT Regulation Toolkit retrieved from http://www.ictregulationtoolkit.org/en/Section.3160.html last accessed $17 / 1 / 2012$

International Telecommunications Union (2010) 'Nigeria is increasingly connected' retrieved from http://www. itu.int/net/itunews/issues/2010/01/31.aspx 
Internet World Stats (2012) 'Internet Users in Africa' retrieved from http://www.internetworldstats.com /stats1.htm

Ituen, I. (2010) 'Slow Internet Speed Impedes Nigeria's Technological Growth' retrieved from http://www.jangola. com/index.php?option=com_content\&view=article\&id=234: slow-internet-speed -impedes-nigerias-technological-growth\&catid $=5 \overline{0}$ : technology $\&$ I temid $=108$

Mishra, M. K (2009) 'Use and Importance of Internet in University of Maidugurl retrieved from http://firstmonday.org/htbin/cgiwrap/bin/ojs/index.php/fm/article/view/2301/2118

National Open University of Nigeria (2013) 'About NOUN - About us' retrieved from http://www.nou.edu.ng/noun/About\% 20NOUN/contents/About\% 20us.html

National Open University of Nigeria (2013) 'About NOUN - Facts and Figures' retrieved from http://www.nou.edu.ng/noun/About\% 20NOUN/contents/facts_figure\% 20.html

National Open University of Nigeria (2013) 'Taking the Electronic Exam at NOUN' retrieved from http://www.nou.edu.ng/noun/e-exam/index.html

Nigerian Communication Act CAP N97, Laws of the Federation of Nigeria 2004

Ogunu, M. A. 'The Development of University Education in Nigeria: A Statistical Analysis' retrieved from http://www.unilorin.edu.ng/journals/education/ije/dec1990/THE\% 20DEVELOPMENT\% 200F\% 20UN IVERSITY\% 20EDUCATION\% 20I N\% 20NIGERIA\% 20\% 20A\% 20STATISTICAL\% 20ANALYSI S.pdf

Oni, A. (2010) 'Enhancing Access To Tertiary Education In Nigeria: Exploring The Establishment Of Nigerian Campuses of Foreign Universities' retrieved from http://adetunjioni.blogspot.com /2010/07/normal-0-microsoftinternetexplorer4.html

Open University (2006) 'Open University retains number one ranking for student satisfaction' retrieved from http://www3.open.ac.uk/media/fullstory.aspx?id=9376

Scholargist.com, May $4^{\text {th }} 2013$ 'JAMB releases 2013 Official Results Statistics - Read This! retrieved from http://www.myscholarsgist.com/2013/05/jamb-releases-2013-official-results. html\#sthash. MQHoMIz 3.BowGVRil.dpbs

The Nation Newspapers online report of February 26th 2013 'Nigerians need access to post-secondary education' retrieved from http://thenationonlineng.net/new/nigerians-need-access-to-postsecondary -education/

The Nation Newspapers online report of May 4th 2013 'UTME: Only 10 candidates scored 300 and above as JAMB releases results ... withholds 12,110 ' retrieved from http://thenationonlineng.net/new /utme-only-10-candidates-scored-300-and-above-as-jamb-releases-results-withholds-12110/

Universal Access and Universal Service Regulations 2007

United Service Provision Fund 'The Universal Service Provision Fund' retrieved from http://www.uspf.gov.ng/index.php?categoryid=12\&p2_articleid=1

Vanguard Newspapers Online Report of November $3^{\text {rd }} 2009$ 'FG Equips 474 schools with Internet Facilities' retrieved from http://www.vanguardngr.com/2009/11/fg-equips-474-schools-withinternet-facilities/

Vanguard Newspapers online report (2012) 'UTME: 1.5 million students battle for 500,000 admission slots' retrieved from http://www.vanguardngr.com/2012/03/utme-1-5-million-students-battle-for500000-admission-slots/\#sthash.sK2pSDTM.dpuf 
